Technical Note

\title{
Photon beam commissioning of an Elekta Synergy linear accelerator
}

\author{
Md Abdullah AL MASHUD ${ }^{1}$, M TARIQUZZAMAN $^{2, a}$, M JAHANGIR ALAM ${ }^{3}$, GA ZAKARIA ${ }^{4}$ \\ ${ }^{I}$ Dept. of Applied Physics, Electronics \& Communication Engineering, Islamic University, Kushtia-7003, Bangladesh \\ ${ }^{2}$ Dept. of Information and Communication Engineering, Islamic University, Kushtia-7003, Bangladesh \\ ${ }^{3}$ Medical Physics Division, Dept. of Radiation Oncology, Ahsania Mission Cancer \& General Hospital, Uttara, Dhaka \\ ${ }^{4}$ Dept. of Medical Radiation Physics, Gummersbach Hospital, Academic Teaching Hospital University of Cologne, \\ Gummersbach, Germany \\ ${ }^{a}$ E-mail address: mtareq@ice.iu.ac.bd
}

(received 16 January 2017; revised 16 February, 10 August, and 16 September 2017; accepted 19 September 2017)

\begin{abstract}
The aim of this study is to present the results of commissioning of Elekta Synergy linear accelerator (linac). The acceptance test and commissioning were performed for three photon beams energies $4 \mathrm{MV}, 6 \mathrm{MV}$ and $15 \mathrm{MV}$ and for the multileaf collimator (MLC). The percent depth doses (PDDs), in-plane and cross-plane beam profiles, head scatter factors $(\mathrm{Sc})$, relative photon output factors (Scp), universal wedge transmission factor and MLC transmission factors were measured. The size of gantry, collimator, and couch isocenter were also measured.
\end{abstract}

Key words: commissioning; accuracy; output; LINAC; transmission factor; in-plane and cross-plane.

\section{Introduction}

Elekta Synergy accelerator is produced by Elekta (Elekta Oncology Systems, Crawley, UK). A few hundred of such accelerators are now used clinically. The Elekta Synergy can deliver photon and electron beams. The accelerator may be used to irradiate a very complex targets in $3 \mathrm{D}$ conformal and Intensity Modulation mode. Before first clinical use according to international recommendations the acceptance and commissioning tests have to be performed. Later the quality control test have to be performed regularly. In this study, we present the results of dosimetric and mechanical tests for Elekta Synergy accelerator installed in Ahsania Mission Cancer \& General Hospital in Dhaka, Bangladesh. In our study, we proposed the systematic steps of commissioning of Elekta Synergy linear accelerator for high energies photon beam only.

\section{Materials and Methods}

The Elekta Synergy is a digital linear accelerator that has capable of delivering $4 \mathrm{MV}, 6 \mathrm{MV}$ and $15 \mathrm{MV}$ photon beams. It has a pair of sculpted diaphragms mounted orthogonal to the multileaf collimator with maximum field size of $40 \times 40 \mathrm{~cm}^{2}$. The thickness of tungsten MLCs in the Agility collimator is $9 \mathrm{~cm}$ and the leaf speed is $3.5 \mathrm{~cm} / \mathrm{s}$. The accurate position of the leaves ensures the Rubicon optical tracking system [1,2]. The primary collimator speed of Agility collimator is $9 \mathrm{~cm} / \mathrm{s}$. The clearance of isocenter is $45 \mathrm{~cm} \mathrm{[3].} \mathrm{All} \mathrm{measurements}$ were made at gantry and collimator angle of $0^{\circ}$.
The measurements were performed according to the AAPM TG-106 recommendations [4]. A PTW MP3-M water tank (PTW, Freiburg, Germany) with a scanning capacity of $50 \times 50 \times 40 \mathrm{~cm}^{3}$ was used. The PDD measurements were made using PTW Semiflex 31010 chamber with a 0.125 cc active volume. As a reference detector the PTW Semiflex 31010 ion chamber was used. For larger field sizes $0.6 \mathrm{cc}$ Farmer type ion chamber SN 009016 and for very small field sizes PTW p diode with active volume $0.03 \mathrm{~mm}^{3}$ was used. The acquisition sampling times have been set to $0.3 \mathrm{~s}$ and $0.6 \mathrm{~s}$ for PTW Semiflex and PTW p diode respectively.

The PTW's MEPHYSTO $\mathrm{mc}^{2}$ navigation software was used for processing all scanned PDD and profile scans. The PDD data have been interpolated to $0.2 \mathrm{~mm}$ spacing and normalized to $100 \%$ at the depth of maximum dose $\left(\mathrm{d}_{\max }\right)$.

\section{A. Mechanical tests}

The mechanical check is a part of linac commissioning. The coincidence of light field and digital readout has been checked by aligning graph paper at $100 \mathrm{~cm}$ SSD to the crosshairs. TG142 recommends the tolerances of $2 \mathrm{~mm}$ for symmetric jaws and $1 \mathrm{~mm}$ for individual asymmetric jaws [5]. The coincidence between mechanical front pointer and the optical distance indicator was measured at several SSDs in the range between $85 \mathrm{~cm}, 90 \mathrm{~cm}$ and $100 \mathrm{~cm}$. According to the TG-142 recommendation the tolerance for optical distance indicator is $1 \mathrm{~mm}$ with a resolution of $1 \mathrm{~cm}$. The collimator and gantry were fixed at zero degree [6]. 


\section{B. Radiation/mechanical isocentricity}

The coincidence of radiation and the mechanical isocenters of the gantry, collimator and couch was measured using star short analysis. A Gafchromic film was used. The film was exposed to five or to six nonoverlapping fields of $0.5 \times 20 \mathrm{~cm}^{2}$ that defined by the secondary collimator and MLCs respectively using 100 monitoring units (MU). For various gantry, collimator and couch angles the process has been repeated. The film was scanned with Vidar scanner. The scanning procedure was based on the recommendations given in TG-55 [7]. TG142 recommended the tolerance of congruence of radiation and mechanical isocenter of $2 \mathrm{~mm}$ diameter.

\section{Characterizations of PDDs and profiles}

The photon PDDs and profiles were measured for square fields sizes of $1 \mathrm{~cm}, 2 \mathrm{~cm}, 3 \mathrm{~cm}, 4 \mathrm{~cm}, 5 \mathrm{~cm}, 7 \mathrm{~cm}, 10 \mathrm{~cm}, 15 \mathrm{~cm}, 20$ $\mathrm{cm}, 30 \mathrm{~cm}$ and $40 \mathrm{~cm}$ per side. The in-plane and cross-plan profiles were measured for the same set of field sizes as PDDs at depth of $\mathrm{d}_{\max }, 5 \mathrm{~cm}, 10 \mathrm{~cm}$ and $20 \mathrm{~cm}$. The MEPHYSTO mc2 (PTW) software was used to process the raw profiles' scans. The smoothing filter was used and the data were interpolated in steps of $0.2 \mathrm{~mm}$. Flatness, symmetry and penumbra were measured within the central $80 \%$ of the full width at half maximum (FWHM) of the processed profile [8]. The flatness, symmetry and penumbra were measured as a maximum ratio between any two points $\left(100 \times D_{\max } / D_{\min }\right)$, the maximum ratio between any two symmetric data points $\left(100 \times \mathrm{D}_{(\mathrm{x})} / \mathrm{D}_{(-\mathrm{x})}\right)_{\max }$ and the spatial distance between $80 \%$ and $20 \%$ of the profile for flattened beam respectively $[9,10]$.

\section{Output factors}

Head scattered factors $\left(S_{c}\right)$ were measured in air using PTW Semiflex 31010 chamber with brass buildup caps. The wall thickness of build-cup was sufficient to ensure the charged particle equilibrium [11,12]. The HSFs were measured for different clinical field sizes. The output factors $\left(S_{c p}\right)$ were measured at $d_{\max }$. For the smallest field sizes the measurements of output factors were made with PTW p diode. For larger field sizes the PTW Semiflex 31010 chamber was used. The output factors were measured at $90 \mathrm{~cm} \mathrm{SSD}$ and at $10 \mathrm{~cm}$ depth. The 100 MUs were delivered. The output factors were normalized to $10 \times 10 \mathrm{~cm}^{2}$ field size [13].

\section{E. Measurements for the universal wedge}

Elekta Synergy was equipped with 60 degree universal wedge mounted in the gantry head that moves in effective wedge angle [14]. In the wedge field the largest field size is $30 \times 40$ $\mathrm{cm}^{2}$. The PDD curves, in-plane and cross-plane profiles have been measured for the filed sizes $5 \times 5 \mathrm{~cm}^{2}, 10 \times 10 \mathrm{~cm}^{2}, 15 \times 15$ $\mathrm{cm}^{2}, 20 \times 20 \mathrm{~cm}^{2}, 20 \times 30 \mathrm{~cm}^{2}$ and $30 \times 40 \mathrm{~cm}^{2}$ at $90 \mathrm{~cm} \mathrm{SSD,} 10$ $\mathrm{cm}$ depth and 100 MUs. The relative wedge factors were measured in relation to $10 \times 10 \mathrm{~cm}^{2}$ field.

\section{F. MLC characterization}

The MLC transmission was measured using PTW Semiflex chamber (active volume $0.3 \mathrm{cc}$ ) and PTW MP-3 water tank. The gantry was set to zero degree and collimator set at $90^{\circ}$ and the tank surface was at $100 \mathrm{~cm}$ distance. The chamber was placed at a depth of $\mathrm{d}_{\max }$ and open field profiles were measured perpendicularly to CAX of $10 \times 10 \mathrm{~cm}^{2}$ field size. The in-plane and cross-plane was scanned at the identical setup but the MLCs closed at a distance of $15 \mathrm{~cm}$ away from the CAX [15]. The maximum transmission for MLCs is $1 \%$ recommended by IEC [16].

The spoke shot of MLC was performed using a Gafchromic film for five to six non-overlapping field of $0.5 \times 20 \mathrm{~cm}^{2}$ which defined by the MLCs and secondary collimator, respectively, using 100 MUs. For all energies the process was repeated. RIT software was used to perform the analysis. The acceptable tolerance is $2 \mathrm{~mm}$ in diameter [5].

\section{Results}

\section{A. Mechanical test}

The largest deviation in digital readout of the gantry and collimator angles was $0.2^{\circ}$, which is lower than $0.5^{\circ}$ tolerance. The couch movement deviations along the three axes were 0.8 $\mathrm{mm}$ which is less than $1 \mathrm{~mm}$ tolerance. The lateral and sagittal lasers were verified within the $1 \mathrm{~mm}$ tolerance. For the field sizes $5 \times 5 \mathrm{~cm}^{2}$ up to $40 \times 40 \mathrm{~cm}^{2}$ were found the largest deviation between light field and digital readout to be $1 \mathrm{~mm}$. The optical distance indicator was verified from $85 \mathrm{~cm}$ to $100 \mathrm{~cm}$ against the mechanical front pointer. The largest deviation was $0.8 \mathrm{~mm}$ which is less than $1 \mathrm{~mm}$ tolerance. The coincidences of light field and radiation field were within $1 \mathrm{~mm}$ for symmetric jaws and $0.5 \mathrm{~mm}$ for asymmetric jaws settings.

\section{B. Radiation/mechanical isocentricity}

The congruence of the radiation and mechanical isocenter for gantry, collimator and couch were $1 \mathrm{~mm}, 0.8 \mathrm{~mm}$ and $0.8 \mathrm{~mm}$ diameter respectively.

\section{Characterizations of PDDs and profiles}

In Figure 1 the measured PDDs for $10 \times 10 \mathrm{~cm}^{2}$ field size for 4 $\mathrm{MV}, 6 \mathrm{MV}$ and $15 \mathrm{MV}$ are shown. The photon beam parameters including $d_{\max }, P D D$ at $5 \mathrm{~cm}, 10 \mathrm{~cm}$ and $20 \mathrm{~cm}$ depth for a $10 \times 10 \mathrm{~cm}^{2}$ field of three energies are summarized in Table 1. It shows that the value of $\mathrm{D}_{20} / \mathrm{D}_{5}$ is increased with energy. In Figure 2 in-plane profiles for 2, 5, 10, 15, 20 and $30 \mathrm{~cm}$ square fields acquired at $90 \mathrm{~cm} \mathrm{SSD}$ and at $10 \mathrm{~cm}$ depth and collimator angle and gantry of zero degree for all three energies are shown. The characteristics of in-plane and crossplane profile included flatness, symmetry and average penumbra values for $10 \times 10 \mathrm{~cm}^{2}$ field are summarized in Table 2. It shows that the cross-plane penumbra values were higher than the in-plane penumbra values by $1.6 \pm 0.4 \mathrm{~mm}$. The values of flatness and symmetry were almost identical. 


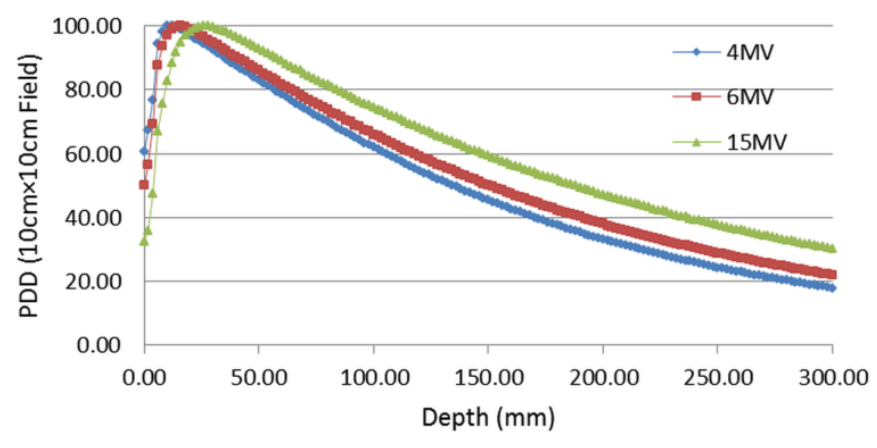

Figure 1. PDD curves for $4 \mathrm{MV}, 6 \mathrm{MV}$ and $15 \mathrm{MV}$ photon beams for $10 \times 10 \mathrm{~cm}^{2}$ field at $90 \mathrm{~cm}$ SSD.
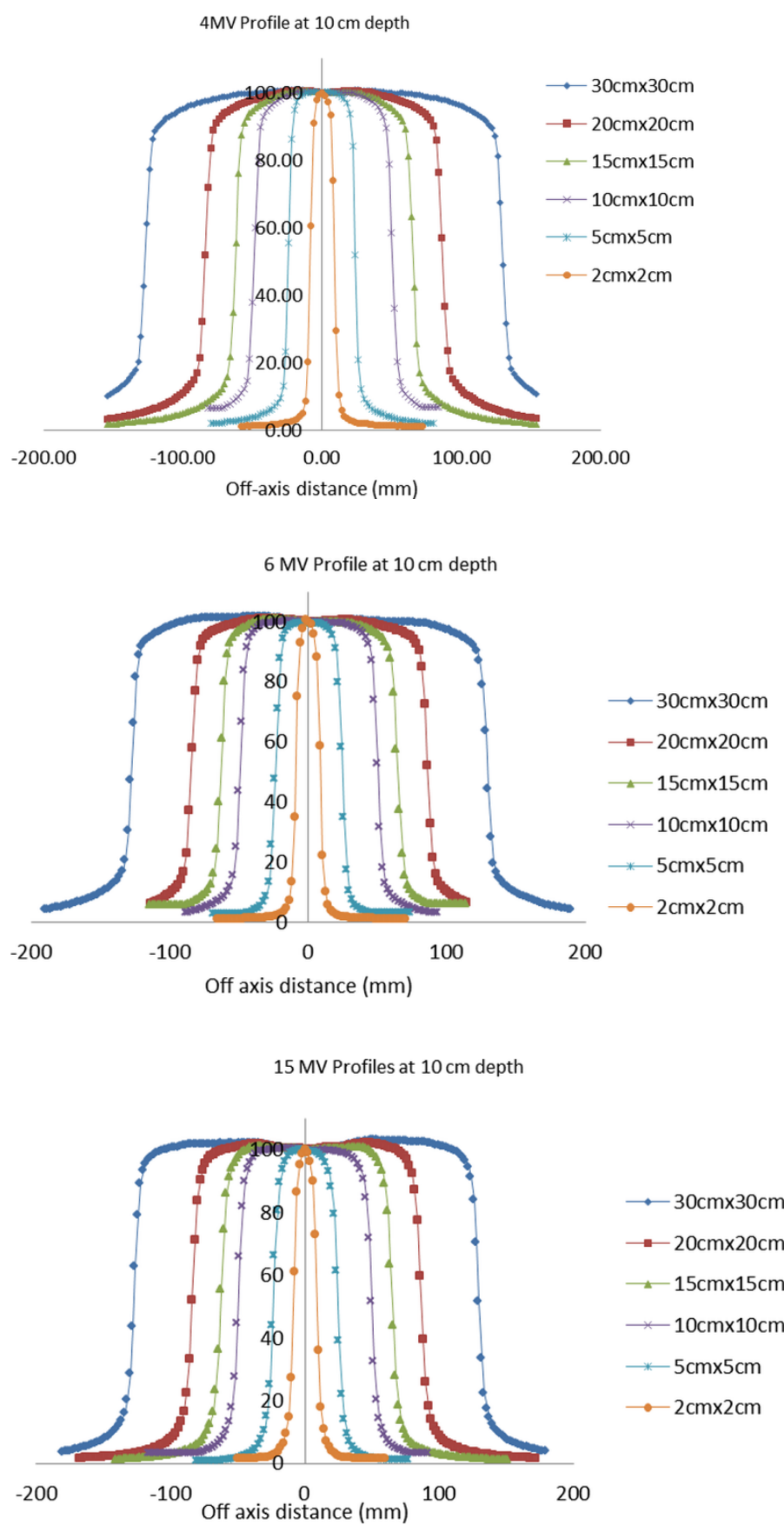

Figure 2. In-plane profiles for $4 \mathrm{MV}, 6 \mathrm{MV}$ and $15 \mathrm{MV}$ photon beams for square field sizes $2,5,10,15,20$ and $30 \mathrm{~cm}$ measured at a depth of $10 \mathrm{~cm}$.

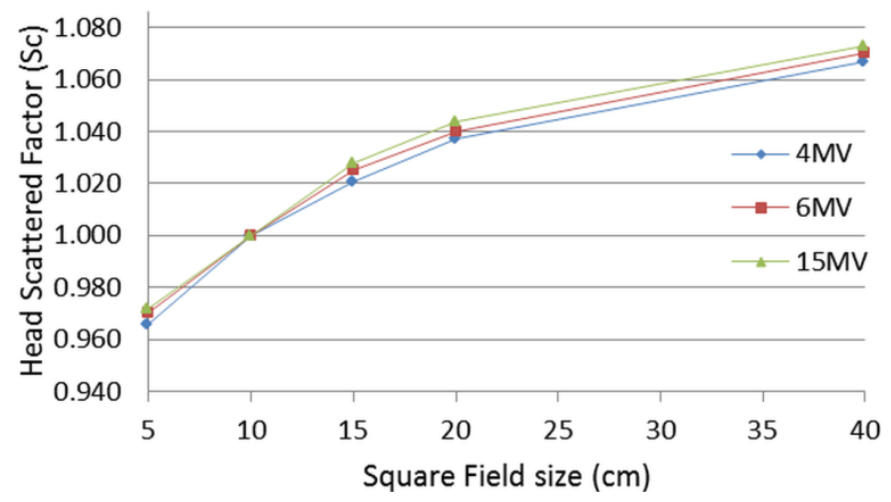

Figure 3. Head scattered factor $\left(S_{c}\right)$ for square field sizes from $5 \mathrm{~cm}$ up to $40 \mathrm{~cm}$ for the three photon energies.

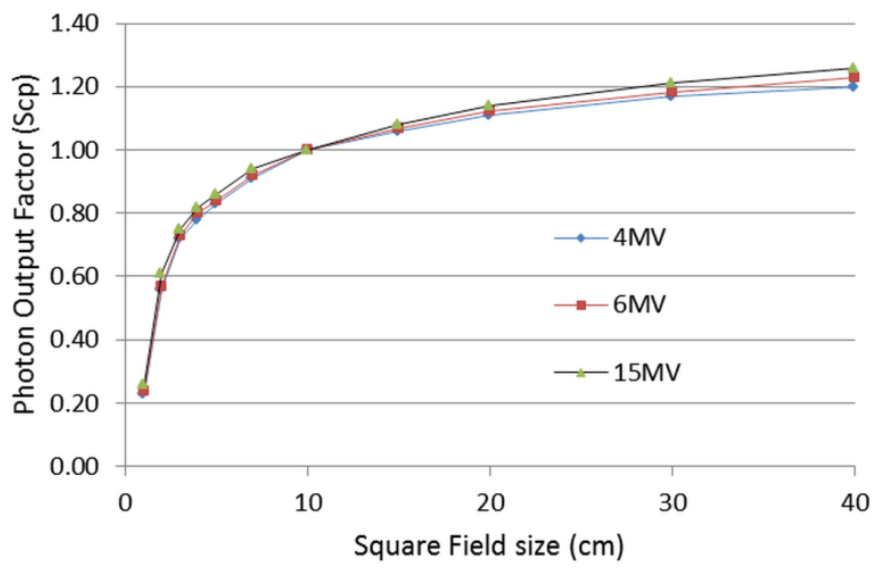

Figure 4. Phantom output factor $\left(S_{\mathrm{cp}}\right)$ for square field sizes from $1 \mathrm{~cm}$ up to $40 \mathrm{~cm}$ for the three energies.

Table 1. Photon beam parameters: $d_{\max }$, PDD at 5, 10, and $20 \mathrm{~cm}$ depths and $D_{20} / D_{5}$ ratio for $10 \times 10 \mathrm{~cm}^{2}$ field for three photon energies.

\begin{tabular}{cccccc}
\hline $\begin{array}{c}\text { Energy } \\
(\mathbf{M V})\end{array}$ & $\begin{array}{c}\mathbf{d}_{\mathbf{m a x}} \\
(\mathbf{c m})\end{array}$ & $\begin{array}{c}\text { PDD } \\
(\mathbf{5} \mathbf{~ c m})\end{array}$ & $\begin{array}{c}\text { PDD } \\
(\mathbf{1 0} \mathbf{~ c m})\end{array}$ & $\begin{array}{c}\text { PDD } \\
(\mathbf{2 0} \mathbf{~ c m})\end{array}$ & $\mathbf{D}_{\mathbf{2 0}} / \mathbf{D}_{\mathbf{5}}$ \\
\hline 4 & 1.2 & 83.00 & 61.90 & 33.10 & 0.40 \\
6 & 1.5 & 86.10 & 66.00 & 37.90 & 0.44 \\
15 & 2.7 & 92.90 & 74.50 & 47.20 & 0.50 \\
\hline \hline
\end{tabular}

Table 2. Flatness (\%), symmetry (\%) and penumbra (mm) obtained from measurements of in-plane and cross-plane profiles for $10 \times 10 \mathrm{~cm}^{2}$ field at a depth of $10 \mathrm{~cm}$.

\begin{tabular}{|c|c|c|c|c|c|c|}
\hline \multirow{2}{*}{$\begin{array}{c}\text { Energy } \\
\text { (MV) }\end{array}$} & \multicolumn{2}{|c|}{$\begin{array}{c}\text { Flatness } \\
(\%)\end{array}$} & \multicolumn{2}{|c|}{$\begin{array}{c}\text { Symmetry } \\
(\%)\end{array}$} & \multicolumn{2}{|c|}{$\begin{array}{c}\text { Average Penumbra } \\
(\mathrm{mm})\end{array}$} \\
\hline & In-plane & $\begin{array}{l}\text { Cross- } \\
\text {-plane }\end{array}$ & In-plane & $\begin{array}{l}\text { Cross- } \\
\text {-plane }\end{array}$ & In-plane & $\begin{array}{l}\text { Cross- } \\
\text {-plane }\end{array}$ \\
\hline 4 & 105.5 & 106.42 & 100.01 & 100.13 & 6.18 & 8.08 \\
\hline 6 & 104.21 & 105.21 & 100.21 & 100.00 & 6.37 & 8.22 \\
\hline 15 & 105.30 & 107.40 & 100.37 & 100.92 & 7.26 & 8.33 \\
\hline
\end{tabular}

Table 3. Relative wedge factors for field sizes $5 \times 5 \mathrm{~cm}^{2}$ up to $30 \times 40$ $\mathrm{cm}^{2}$ for 4,6 and $15 \mathrm{MV}$ beams

\begin{tabular}{ccccccc}
\hline \hline \multirow{2}{*}{$\begin{array}{c}\text { Energy } \\
(\mathbf{M V})\end{array}$} & $\mathbf{5 \times 5}$ & $\mathbf{1 0 x 1 0}$ & $\mathbf{1 5 x 1 5}$ & $\mathbf{2 0 \times 2 0}$ & $\mathbf{2 5 x 3 0}$ & $\mathbf{3 0 \times 4 0}$ \\
\cline { 2 - 7 } & 0.87 & 1.00 & 1.09 & 1.17 & 1.23 & 1.27 \\
4 & 0.89 & 1.00 & 1.08 & 1.15 & 1.20 & 1.23 \\
6 & 0.89 & 1.00 & 1.07 & 1.13 & 1.16 & 1.19 \\
15 & & & & & & \\
\hline \hline
\end{tabular}




\section{Output factors}

The $S_{c}$ value ranges from 0.968 to 1.046 for $4 \mathrm{MV}, 0.97$ to 1.06 for $6 \mathrm{MV}$ and 0.976 to 1.072 for $15 \mathrm{MV}$.

Figure 4 shows the photon output factors $\left(S_{\mathrm{cp}}\right)$ for square field sizes from $1 \mathrm{~cm}$ up to $40 \mathrm{~cm}$. It shows that the output factor ranges from 0.45 to 1.20 for $4 \mathrm{MV}, 0.47$ to 1.29 for 6 $\mathrm{MV}$ and 0.50 to 1.35 for $15 \mathrm{MV}$.

\section{E. Universal wedge - relative wedge factors}

The wedge transmission factors were $0.24,0.26$ and 0.28 for 4 $\mathrm{MV}, 6 \mathrm{MV}$ and $15 \mathrm{MV}$ photon beams respectively.

The measured relative wedge factors ranged between 0.87 and 1.27 , between 0.89 and 1.23 , and between 0.89 and 1.19 for $4 \mathrm{MV}, 6 \mathrm{MV}$ and $15 \mathrm{MV}$ photon beam respectively as tabulated in Table 3. It shows that the range of relative wedge factors decreases with increasing photon beam energy.

\section{F. MLC characterization}

The average transmissions were $0.5 \%, 0.6 \%$ and $0.6 \%$ for 4 $\mathrm{MV}, 6 \mathrm{MV}$ and $15 \mathrm{MV}$ photon beams respectively.

\section{Discussion}

The dependence of the measured PDDs and beam profiles on energies were consistent with the data for Varian True Beam [17]. The depth of maximum dose for $10 \times 10 \mathrm{~cm}^{2}$ field size increases with energy. The $\mathrm{D}_{20} / \mathrm{D}_{10}$ values for $10 \times 10 \mathrm{~cm}^{2}$ field size increases with energy. Similar results were obtained by Kragl et al. [18]. The symmetry, flatness and penumbra were similar to obtained for Varian True Beam [20]. The range of head scattered factors, output factors and relative wedge factors agree with the observation obtained in studies [21,22]. The MLC transmissions agreed with Thomson's et.al. results [15].

\section{Summary}

In this study we present the results of commissioning of Elekta Synergy accelerator. This work may help others for efficient commissioning of any type of accelerator.

\section{Acknowledgement}

This research is supported by Ministry of National Science and Technology, Government of the People's Republic of Bangladesh. (No. 39.012.002.01.03.021.2014-07)

\section{References}

[1] Narayanasamy G, Saenz D, Cruz W, et al. Commissioning an Elekta Versa HD linear accelerator. J Appl Clin Med Phys. 2016;17(1):179-191.

[2] Allen J. White Paper: High Dose Rate mode (Flattening Filter Free) Radiotherapy Clinical advantages of High Dose Rate mode, available with Agility ${ }^{\mathrm{TM}}$ on Elekta's Versa $\mathrm{HD}^{\mathrm{TM}}$ linear accelerator [white paper]. 2014.

[3] Boda-Heggemann J, Mai S, Fleckenstein J, et al. Flattening-filter-free intensity modulated breath-hold image-guided SABR (Stereotactic ABlative Radiotherapy) can be applied in a 15-min treatment slot. Radiother Oncol. 2013;109(3):505-509.

[4] Das IJ, Cheng CW, Watts RJ, et al. Accelerator beam data commissioning equipment and procedures: report of the TG-106 of the Therapy Physics Committee of the AAPM. Med Phys. 2008;35(9):4186-4215.

[5] Klein EE, Hanley J, Bayouth J, et al. Task Group 142 report: quality assurance of medical accelerators. Med Phys. 2009;36(9):41974212.

[6] Almond PR, Biggs PJ, Coursey BM, et al. AAPM's TG-51 protocol for clinical reference dosimetry of high-energy photon and electron beams. Med Phys. 1999;26(9):1847-1870.

[7] Niroomand-Rad A, Blackwell CR, Coursey BM, et al. Radiochromic film dosimetry: recommendations of AAPM Radiation Therapy Committee Task Group 55. Med Phys. 1998;25(11):2093-2115.

[8] International Electrotechnical Commission. Medical electrical equipment. Part 2: Particular requirements for the safety of gamma beam therapy equipment. IEC 60601-2-11. Geneva, Switzerland: IEC; 1987.

[9] Pönisch F, Titt U, Vassiliev ON, et al. Properties of unflattened photon beams shaped by a multileaf collimator. Med Phys. 2006;33(6):1738-1746.

[10] Stathakis S, Esquivel C, Gutierrez A, et al. Treatment planning and delivery of IMRT using 6 and 18 MV photon beams without flattening filter. Appl Radiat Isot. 2009;67(9):1629-1637.

[11] Weber L, Nilsson P, Ahnesjö A. Build-up cap materials for measurement of photon head-scatter factors. Phys Med Biol. 1997;42(10):1875-1886.

[12] Jursinic PA. Measurement of head scatter factors of linear accelerators with columnar miniphantoms. Med Phys. 2006;33(6):17201728.

[13] Dieterich S, Sherouse GW. Experimental comparison of seven commercial dosimetry diodes for measurement of stereotactic radiosurgery cone factors. Med Phys. 2011;38(7):4166-4173.

[14] Phillips MH, Parsaei H, Cho PS. Dynamic and omni wedge implementation on an Elekta SL linac. Med Phys. 2000;27(7):1623-1634. 
[15] Thompson CM, Weston SJ, Cosgrove VC, Thwaites DI. A dosimetric characterization of a novel linear accelerator collimator. Med Phys. 2014;41(3):031713.

[16] International Electrotechnical Commission. Medical electrical equipment — Part 2.1. Particular requirements for the basic safety and essential performance of electron accelerators in the range $1 \mathrm{MeV}$ to $50 \mathrm{MeV}$. IEC 60601-2-1 Ed. 3.0. Geneva, Switzerland: IEC; 2009.

[17] Chang Z, Wu Q, Adamson J, et al. Commissioning and dosimetric characteristics of TrueBeam system: composite data of three TrueBeam machines. Med Phys. 2012;39(11):6981-7018.

[18] Kragl G, af Wetterstedt S, Knäusl B, et al. Dosimetric characteristics of 6 and 10 MV unflattened photon beams. Radiother Oncol. 2009;93(1):141-146.

[19] Benedict SH, Yenice KM, Followill D, et al. Stereotactic body radiation therapy: the report of AAPM Task Group 101. Med Phys. 2010;37(8):4078-4101.

[20] Glide-Hurst C, Bellon M, Foster R, et al. Commissioning of the Varian TrueBeam linear accelerator: a multi-institutional study. Med Phys. 2013;40(3):031719.

[21] Cashmore J. The characterization of unflattened photon beams from a 6 MV linear accelerator. Phys Med Biol. 2008;53(7):19331346.

[22] Vassiliev ON, Titt U, Pönisch F, et al. Dosimetric properties of photon beams from a flattening filter free clinical accelerator. Phys Med Biol. 2006;51(7):1907-1917. 